\title{
Project Evaluation and Uncertainty in Practice: A Statistical Analysis of Rate-of-Return Divergences of 1,015 World Bank Projects
}

\author{
Gerhard Pohl and Dubravko Mihaljek
}

\begin{abstract}
This article analyzes the World Bank's expenence with project evaluation for a sample of 1,015 projects by comparing estimated rates of return at appratsal with reestimated rates of return when construction works are completed, usually $S$ to 10 years after appraisal. The analysis highlights the high degree of uncertainty in project analysis. A wide range of variables has been introduced to explain the observed divergence in appraisal and reestimated rates of return, but only a relatively small part of the divergence can be explained, even with the benefit of hindsight. Project analysis thus has to cope with a large degree of uncertainty, which the traditional methods of project evaluation and selection have not been able to reduce.
\end{abstract}

The World Bank's long history of project financing provides a unique opportunity to quantify the level of uncertainty in public sector investment projects in developing countries and to assess the effects of cost-benefit analysis on investment decisions. For projects whose costs and benefits are reasonably amenable to quantification, Bank staff calculate economic rates of return at appraisal and again at project completion (after construction works have been completed and the project begins normal operations). For more than 1,000 projects, economic rate of return estimates now are available for both appraisal and completion. The difference between these two estimates provides an interesting empirical measure of the uncertainty of development projects financed by the World Bank.

Cost-benefit analysis is a standard appraisal tool for selecting development projects at the World Bank and other development finance institutions. Several governments also have adopted these techniques in planning public investment projects. The World Bank broadly follows the Little-Mirrlees (1968, 1974) methodology, which expanded earlier approaches to cost-benefit analysis to take

Gerhard Pohl is with the Geneva Office of the World Bank. At the time of writing, Dubravko Mihaljek was with the Department of Economics at the University of Pitrsburgh and the Economics Institute in Zagreb. Research for this study was initiated while Dubravko Mihaljek was a summer assistant in the Economic Advisory Staff of the Wortd Bank. Helpful comments by the participants in a World Bank seminar and anonymous referees are gratefully acknowledged.

(c) 1992 The International Bank for Reconstruction and Development/THE WORLD BANK 
account of economic distortions typically prevailing in developing countries. Squire and van der Tak (1975) refined the methodology further to take account of income distribution effects, as did Reutlinger (1970) to take account of uncertainty. More recent generalizations and refinements of the theory of cost-benefit analysis are reviewed, for example, in Drèze and Stern (1987) and Squire (1989).

The theory of cost-benefit analysis provides a rigorous conceptual framework in which to evaluate public expenditure programs and investment projects (Little and Mirrlees 1991). Practical applications, however, depart quite substantially from these ideals because some of the key parameters are difficult to estimate in practice. In theory, for example, net discounted benefits at the accounting rate of interest would be the appropriate criterion to decide whether to carry out a particular project in the Little-Mirrlees framework. In practice it is quite difficult to estimate the accounting rate of interest reasonably accurately. Equating the accounting rate of interest with the (highest) rate that just exhausts available investment funds, as suggested early on by Little and Mirrlees, is conceptually clear and simple, but few, if any, developing countries have a comprehensive ranking of available public investment opportunities. Returns on past public sector investments may be misleading due to poor investment decisions or inappropriate economic policies. Project proposals by sectoral agencies, however, may be padded with optimistic assumptions and imply an exaggerated rate of return.

Since public sector and economywide rate-of-return estimates vary considerably across countries (depending on endowments and, more important, on policies), the Bank uses the internal rate of return calculated at shadow prices or, for short, the economic rate of return as an important, but not exclusive, decision criterion. With few exceptions the World Bank finances only projects that have an estimated economic rate of return of at least 10 percent at appraisal (in constant prices).

Of course projects financed by the World Bank are not necessarily representative of public sector investments in developing countries. Projects submitted by governments for Bank financing may primarily include projects with aboveaverage rates of return and below-average risks. This may be particularly true in large countries (such as India), where Bank-financed projects represent only a very small part of the public investment program.

Although a considerable degree of uncertainty is to be expected in implementing development projects, the extent of revealed uncertainty in World Bank projects is striking. Estimates of economic rates of return at appraisal (AERR) are relatively poor predictors of reestimated rates of return at completion of construction works (RERR). Figure 1, in which each point represents rates of return for one project, shows this relation-most of the points in the figure are below the 45 degree line, that is, most projects have economic rates of return lower at completion than at appraisal.

The reestimated rates of return are not true ex-post rates of return because 
Figure 1. Relation between Appratsal and Reestimated Rates of Return

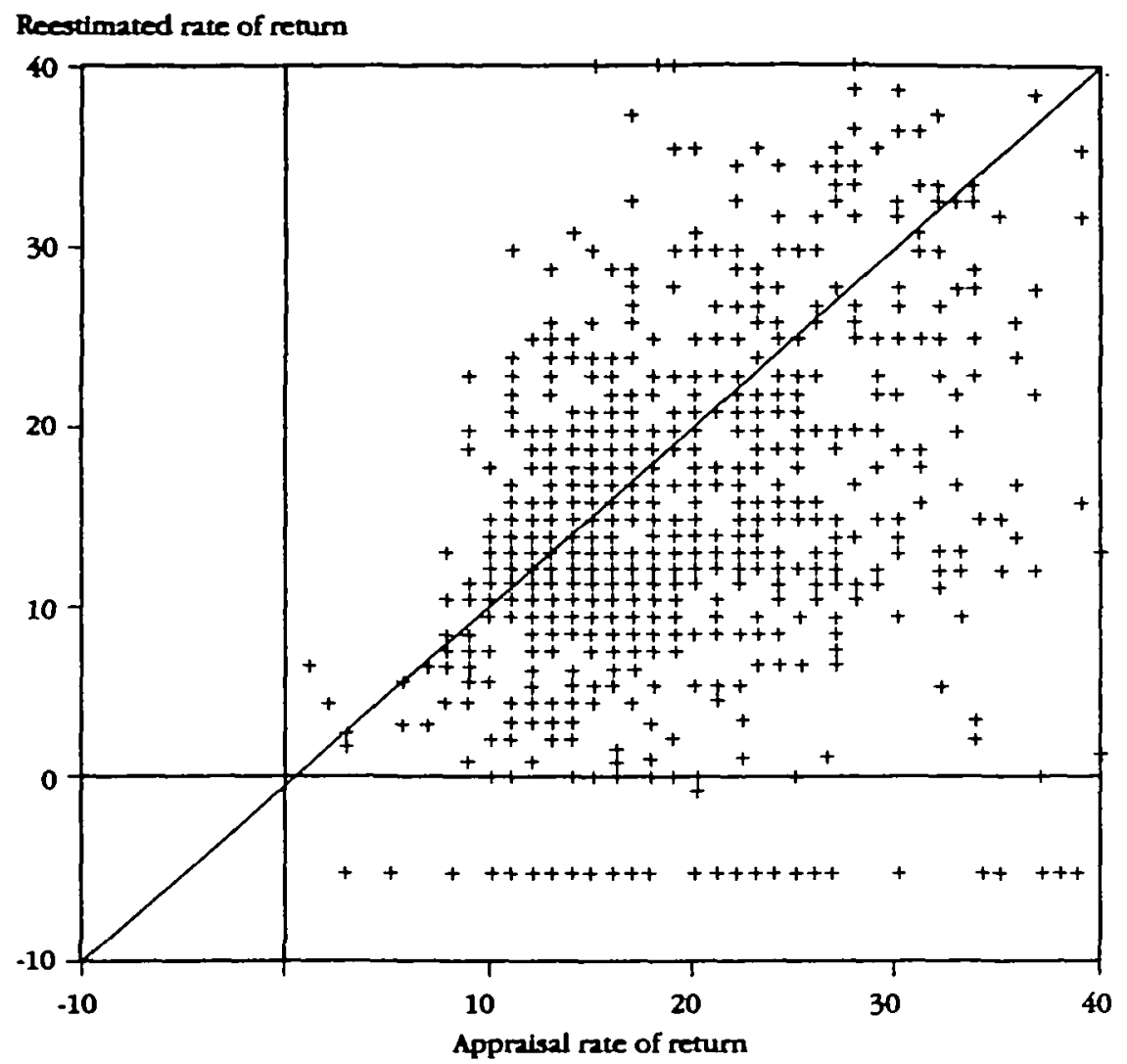

Note: Projects with appratsal or reestmated economic rates of retum greater than 40 percent (about 8 percent of all projects) have been omitted for greater elarity.

Sounce: Authors' calculations.

they are made at the start-up of normal operations. In view of the long life of most investment projects, ex-post estimates can be made only after 10 or more years. However, when the reestimated rates are calculated, the effect of a number of risks already is known (such as investment costs, construction delays, and initial operating performance), and later costs and benefits are more heavily discounted. Because of the long life of most investment projects, the relation between ex-post rates of return and reestimated rates at completion of construction may be as loose as the relation between appraisal and reestimated rates of return.

This article analyzes the differences between appraisal and reestimated rates of return with statistical techniques and provides some initial interpretation of the results. The statistical analysis can capture only factors that are measurable and are applicable to all types of projects. This approach can provide only an 
overview and cannot substitute for project performance audits at the project level. The rate of return of a copper project, for example, will depend strongly on whether actual copper price developments fulfill appraisal expectations. The closest our analysis gets to this is through inclusion of a composite real commodity price index on projects in broad sectors (for example, agriculture).

As discussed in the next two sections, the nature of our data set poses several challenges for statistical analysis. Two most serious ones are the heteroskedasticity of residuals and the censoring of reestimated rates of return. To avoid these problems, we have transformed the dependent and explanatory variables in such a way that the error term is constant, and we have used the maximum likelihood estimation technique within the Tobit regression framework. Tests performed confirm the validity of this approach and therefore give additional weight to our results.

\section{The DATA}

This analysis is based largely on a data base maintained by the Bank's Operations Evaluation Department (OED), an independent unit reporting directly to the Executive Directors. The complete data set includes 2,200 projects for which project completion reports had been issued during $1974-87$ by the respective project departments for audit by the OED on a sample basis. For slightly more than half of these projects, economic rates of return have been calculated by the staff at appraisal and project completion (start-up of normal operations). For the remainder of the projects in the data base (such as technical assistance and structural adjustment loans), economic rates of return were not available, primarily because quantification was deemed infeasible or unjustified. A few projects were excluded because other key variables were missing from the data set, or because other supplementary data were not available. The analysis thus was carried out with a final sample of 1,015 projects for which a complete data set was available. The sample selection is fairly objective and does not appear to bias the results. The only systematic omission is financial intermediation projects, which finance numerous small- and medium-scale industrial and agricultural projects. A similar analysis could, in principle, be carried out for financial intermediation projects, but would involve considerable effort to collect data.

The OED data base was augmented by supplementary variables that were believed to be important explanatory factors of project success, including the Bank's internal ranking of economic management performance by country as of 1978, a country-specific index of price distortions for the 1970s (Agarwala 1983), real commodity price movements, per capita income, and adult literacy rates. The price distortion index was available for 31 countries accounting for 612 projects. A separate analysis was undertaken for this smaller sample. Sectoral and regional dummy variables were introduced as proxies for project characteristics and management performance. 
Table 1. Summary Statistics for 1,015 World Bank Projects

\begin{tabular}{lrrrrr}
\hline & Mean & Median & Maximum & Minimum & $\begin{array}{c}\text { Standard } \\
\text { deviation }\end{array}$ \\
\hline $\begin{array}{l}\text { Economic rate of return (percent) } \\
\quad \text { At appraisal }\end{array}$ & 22 & 18 & 158 & 1 & 13 \\
$\quad$ At project completion & 16 & 14 & 128 & -20 & 13 \\
$\begin{array}{l}\text { Total project cost } \\
\quad \text { US dollar millions, current prices) }\end{array}$ & & & & & \\
$\quad$ At appraisal & 86 & 34 & 3,193 & 1 & 185 \\
$\quad$ At project completion & 102 & 40 & 4,045 & 1 & 233 \\
Nominal cost overrun (percent) & 22 & 10 & 514 & -89 & 46 \\
Unexpected inflation (percent) & 20 & 23 & 38 & -2 & 7 \\
Real cost overrun (percent) & -6 & -11 & 394 & -91 & 34 \\
Time overrun (years) & 2 & 2 & 16 & -4 & 2 \\
Time overrun (percent) & 58 & 46 & 405 & -68 & 56 \\
& & & & & \\
\hline
\end{tabular}

Note: Project completion refers to start-up of normal operations.

Source: Authors' calculations.

Table 1 presents the main descriptive statistics for the data set and shows the wide variety of projects. Economic rates of return are derived, as explained above, as real internal rates of return at economic (shadow) prices. Project costs in the data base are in nominal U.S. dollars and range from about $\$ 1$ million to more than $\$ 4$ billion. Forty percent of the projects are in agriculture, 30 percent in transport, 20 percent in energy, and the rest in industry and urban development. The larger part of the Bank's industrial lending is intermediated through financial institutions. Unfortunately, average rates of return on financial intermediation lending are not systematically available.

Except for construction costs, the medians are fairly close to the averages for the data set. Constant-dollar cost data are not recorded in the data base, although they are available in the project files and have been used to calculate the economic rates of return. Rather than sifting through 1,015 voluminous project files, we have estimated implicit real costs from forecast and actual price developments as well as from other implementation data in the data base (see the appendix).

There is considerable variation in the appraisal rates of return, ranging from only 1 percent for a water supply project in Bombay to 158 percent for a seed project in India (which had a reestimated rate of return at project completion of only 11 percent). The wide range of rates of return both at appraisal and project completion ( -20 to 128 percent) is perhaps surprising. In the more orderly world of economic theory and model-building, one usually assumes that rates of return converge within a fairly narrow range. Ninety percent of all projects have appraisal rates of return in the range of $10-40$ percent, but only about half have reestimated rates of return within this range, which highlights the importance of uncertainty. The average rate of return of World Bank projects has behaved in a 
more orderly way, averaging 22 percent at appraisal and 16 percent at project completion, with fairly small differences from year to year.

For about 5 percent of all projects the reestimated (inrernal) rates of return are negative. For many projects with negative rates of return these are given as -5 percent in the data base, presumably because negative internal rates are highly sensitive to small differences in assumptions and to truncation of the time horizon. The economic interpretation of negative internal rates of return in most cases is a zero rate of return (no increase in output for some large investment). Only if variable costs exceeded benefits (both at shadow prices) would one normally speak of "negative" rates of return, which typically would be due to domestic price distortions (negative value added at international prices).

Although the average reestimated rates of return are satisfactory (16 percent, versus 22 percent at appraisal), there are many projects with low returns ( 25 percent of all projects have reestimated rates of return below 10 percent, 14 percent have below 5 percent, and 8 percent of all projects have zero or negative rates of return). This suggests that considerable benefits could be obtained if the factors that lead to project failure could be identified. Defining project failure is not a simple matter. Some cutoff point for rates of return has to be adopted to distinguish successful from unsuccessful projects. In the Little-Mirrlees framework, that cutoff point would be relatively high (say 10 percent) due to the choice of the numeraire ("uncommitted public income," as opposed to consumption in the UNIDO methodology; see Dasgupta, Marglin, and Sen 1972 and Ray 1984).

World Bank projects have, on average, taken considerably more time to implement (six years) than expected at appraisal (four years), and project costs in U.S. dollars were, on average, 22 percent higher than estimated at appraisal, despite ample physical and price contingencies built into project cost estimates. Project cost overruns and implementation delays thus could be important factors in explaining project performance and the loose relationship between rate-ofreturn estimates at appraisal and project completion.

With the help of the derived real project costs, the reported nominal cost overruns were decomposed into two parts: unexpected changes in the general price level for capital goods and project-specific real cost increases. The latter could be due to an error in project cost estimates, unforeseen difficulties and expenditures, or increases in the scope of projects. Nominal cost overruns mostly are explained by unexpectedly high inflation during the period (primarily the 1970s), with actual prices being 20 percent higher than projected at appraisal. Perhaps surprisingly, the appraisal cost estimates were, on average, too high in real terms. Nominal cost overruns thus are primarily due to unexpectedly high inflation. Real cost variations range from -90 percent (probably largely due to cancellations of project components) to increases of nearly $\mathbf{4 0 0}$ percent (probably reflecting expansion in the scope of projects, rather than faulty cost calculations). 


\section{Statistical Methodology}

The divergence between the appraisal and reestimated rates of return has been analyzed with two types of linear regression; the results from both types of regression are reported in section III. The first consists of regressing the reestimated rates of return at project completion on the appraisal rates of return and several other factors that are thought to influence project performance. Since both the appraisal and reestimated rates of return depend on the same set of other factors, this approach is best interpreted in terms of a "seemingly unrelated regression" model. (See Zellner [1962] for the original contribution; and Wallace, Duane, and Nawaz [1987] for an application similar to this article.)

One statistical problem with the standard ordinary least squares (OLS) estimation of this linear regression model is that residuals calculated from the above data set do not have uniform variance and zero correlation with one another. In the presence of heteroskedasticity the oLs estimator remains unbiased, but it no longer has minimum variance among all linear unbiased estimators. Also the usual formula for the variance-covariance matrix of oLs estimators is incorrect, and therefore the usual estimator of their variance is biased, implying that interval estimation and hypothesis testing using these estimators no longer can be trusted. Intuitively, one would expect larger time and cost overruns to be associated with larger discrepancies in the rates of return. For a wide range of projects the standard deviation of reestimated rates of return increases only moderately with appraisal rates of return (from 9 percentage points for projects with AERRS of 10-20 percent to 14 percentage points for projects with AERRS of $30-40$ percent), but it jumps to 25 percentage points for a small number of projects with higher AERRS.

Several techniques exist to correct the standard errors of estimates (White 1980). We eliminate the problem by transforming the variables in such a way that the error term is constant. Thus in the second type of regression model the dependent variable is the percentage change in the reestimated rate over the appraisal rate of return [(RERR - AERR)/AERR]. This transformation eliminates heteroskedasticity, but at the cost of losing interesting information about the relation between the appraisal and reestimated rates of return. A third approach (not undertaken here) would be to eliminate projects with very high appraisal rates of return, because these may have an extraordinarily strong influence over the results. High AERRS often are due to major changes in expectations and usually involve comparatively small investments (for example, energy conservation, resource discoveries, and technological breakthroughs).

Besides heteroskedasticity, the nature of our data set gives rise to another statistical problem: censoring of reestimated rates of return. From table 1 it appears that the range of variation of reestimated rates of return is wide enough to make plausible the assumption of an approximately normal distribution of residuals. However, there is a considerable piling up (about 7 percent of proj- 
ects) of RERRS at a cutoff point of -5 percent. This reflects the established practice in the World Bank whereby a project deemed to be a complete failure usually is assigned a -5 percent rate of return at completion. ${ }^{1}$

From an econometric point of view, the presence of the cutoff point implies that we are dealing with a censored sample, as some observations of the RERR that correspond to known values of time and cost overruns are not observable, being instead arbitrarily assigned the RERR of -5 percent. The difficulty with ots estimation based on censored data samples is that the least squares estimators of regression parameters are biased and inconsistent, using either the entire sample or the subsample of complete observations. (For analysis of censored data samples see, for example, Maddala [1983] or Judge and others [1985].) These kind of data are best analyzed within the framework of the censored regression model, also known as the Tobit model (Tobin 1958). A number of techniques now exist to estimate Tobit models (see Amemiya 1984). To generate more efficient parameter estimates, we used the maximum likelihood technique, which yields estimators with several desirable asymptotic properties (see, for example, Greene 1990).

The Tobit regression model for our data sample is of the form:

$$
y_{i}= \begin{cases}x_{i}^{\prime} \beta+e_{i} & \text { if } y_{i}>k, \\ 0 & \text { otherwise }\end{cases}
$$

$$
i=1, \ldots T-s
$$

and the corresponding regression function is given by:

$$
E\left(y_{i} \mid x_{i}, y_{i}>k\right)=X_{i}^{\prime} \beta+\sigma \epsilon_{i}
$$

where $y$ is a vector of dependent variables (RERRS or percentage changes thereof over the AERRs), $X$ is a matrix of explanatory variables, $\beta$ is a vector of unknown regression parameters, $\sigma$ is an unknown scale parameter, $e$ and $\epsilon$ are vectors of errors assumed to come from the standard normal distribution, $k$ is the cutoff point ( -5 percent for regressions where RERR is the dependent variable and -1 for regressions where the dependent variable is (RERR AERR)/AERR)), and $s$ observations out of $T$ are unobservable. ${ }^{2}$

1. Another such practice is that projects with appraisal rates of return of less than 10 percent usually are not considered for approval. Theoretically, in the presence of this cutoff point the data set would be truncated: values of time and cost overruns and Rekrs would be known only when AERrs at or above 10 percent were observed, so we could make no inference on the porential performance of projects that were not accepted for financing. However, in the data set there are 46 projects (4.5 percent of the total) that were approved even though they had AERRs of less than 10 percent, so information on normally "unobservable" projects actually is not missing.

2. The log likelihood funcrion for this regression modet is given by:

$$
\ln L=-\left(n_{1} / 2\right)\left[\ln (2 \pi)+\ln \sigma^{2}\right]-\left(1 / 2 \sigma^{2}\right) \Sigma_{1}\left(y_{i}-\beta^{\prime} x_{s}\right)^{2}+\Sigma_{0} \ln \left[1-\Phi\left(\beta^{\prime} x_{i} / \sigma\right)\right]
$$

where $\Phi($.$) is the standard normal amulative distribution function. The first two parts of this function$ correspond to the classical regression for noncensored observations; the last part corresponds to the relevant probabilities for the censored observations (see Amemiya 1973). MLE extimates of this regression model were computed using the LIFEREG procedure of the sAs statistical package, version 6.06 . 


\section{The Models and Estimation Results}

In the simplest model the reestimated economic rate of return is the dependent variable, and the appraisal economic rate of return is the explanatory variable. Additional models are presented with explanatory variables for cost overruns, implementation delays, and unexpected inflation. These explanatory variables are also used in alternative models with a transformed dependent variable. Two of the initial five models are estimated with additional explanatory variables to account for changes in primary commodity prices, economic management factors, and sectoral and geographic differences.

\section{Five Initial Models}

The simplest possible model relates only appraisal and reestimated rates of return and assumes that no other factors have been identified. Thus equation 3 represents model 1 :

$$
\mathrm{RERR}=a+b \mathrm{AERR}+\sigma u .
$$

Models 2 and 3 expand on model 1 to include project cost overruns and implementation delays, which are intuitively linked with poor project performance. Model 2 introduces two variables from the data base: the nominal cost overrun and the time overrun, both in percent. Model 3 introduces two variables that decompose the nominal cost overrun into two components: unexpected inflation and real cost overruns.

Equation 4 gives the format for regressions with the transformed dependent variable (RERR - AERR)/AERR and the transformed explanatory variables ( $X_{t}-$ $\left.X_{t-1}\right) / X_{t-1}$ :

$$
(\mathrm{RERR}-\mathrm{AERR}) / \mathrm{AERR}=a+b^{\prime}\left[\left(X_{t}-X_{t-1}\right) / X_{t-1}\right]+\sigma u
$$

where $t$ denotes the relevant observation at the time of completion (of construction) and $t-1$ the appraisal estimate of that same variable.

Maximum likelihood parameter estimates for models 1 through 5 are given in table 2, with summary statistics obtained from the ols estimates of the regressions. Normal scale parameter $\sigma$ does not have an intuitive economic interpretation, so its estimates are not reported. In all regressions where the dependent variable is RERR, the estimates of $\sigma$ are on the order of about 12 percentage points and are statistically highly significant.

Model 1. The results for model 1 indicate that economic rates of return reestimated at project completion are, on average, considerably lower than appraisal estimates $(b=0.44)$. The intercept is quite large ( 5.88 percentage points), indicating that reestimated rates of return are somewhat higher, relative to appraisal estimates, for projects with low appraisal rates of return. A project with an appraisal rate of return of 10 percent has a reestimated rate of return approximately equal to its appraisal rate of return $(5.88+0.44 \times 10)$, whereas 
Table 2. Maximum Likelihood Estimates for the Initial Five Models

\begin{tabular}{|c|c|c|c|c|c|}
\hline \multirow{3}{*}{$\begin{array}{l}\text { Explanatory variables } \\
\text { and regression statistics }\end{array}$} & \multicolumn{5}{|c|}{ Dependent variable } \\
\hline & \multicolumn{3}{|c|}{$\begin{array}{c}\text { Reestimated economic rate } \\
\text { of return }\end{array}$} & \multicolumn{2}{|c|}{$\begin{array}{l}\text { Change in reestimated } \\
\text { economic rate of return } \\
\text { relative to the appraisal } \\
\text { economic rate of return }\end{array}$} \\
\hline & Model 1 & Madel 2 & Model 3 & Model 4 & Model S \\
\hline \multicolumn{6}{|l|}{ Explanatory variable } \\
\hline Intercept & $\begin{array}{l}5.88 \\
(0.76)\end{array}$ & $\begin{array}{l}5.25 \\
(0.88)\end{array}$ & $\begin{array}{c}8.78 \\
(1.26)\end{array}$ & $\begin{array}{r}-101.42 \\
(7.89)\end{array}$ & $\begin{array}{l}-40.76 \\
(12.72)\end{array}$ \\
\hline Appraisal rate of retum & $\begin{array}{c}0.44 \\
(0.03)\end{array}$ & $\begin{array}{c}0.44 \\
(0.03)\end{array}$ & $\begin{array}{c}0.45 \\
(0.03)\end{array}$ & $\begin{array}{l}\text { n.a. } \\
\text { n.a. }\end{array}$ & $\begin{array}{l}\text { n.a. } \\
\text { n.a. }\end{array}$ \\
\hline Nominal cost overrun & $\begin{array}{l}\text { n.a. } \\
\text { n.a. }\end{array}$ & $\begin{array}{l}0.003 \\
(0.009)\end{array}$ & $\begin{array}{l}\text { n.a. } \\
\text { n.a. }\end{array}$ & $\begin{array}{l}0.07 \\
(0.11)^{\prime \prime}\end{array}$ & $\begin{array}{l}\text { n.a. } \\
\text { n.a. }\end{array}$ \\
\hline Time overrun & $\begin{array}{l}\text { n.a. } \\
\text { n.a. }\end{array}$ & $\begin{array}{l}0.009 \\
(0.007)^{7}\end{array}$ & $\begin{array}{c}0.012 \\
(0.007)\end{array}$ & $\begin{array}{c}0.01 \\
(0.01) \boldsymbol{P}\end{array}$ & $\begin{array}{l}0.03 \\
(0.08)^{\mathrm{a}}\end{array}$ \\
\hline Unexpected inflation & $\begin{array}{l}\text { n.2. } \\
\text { n.a. }\end{array}$ & $\begin{array}{l}\text { n.a. } \\
\text { n.a. }\end{array}$ & $\begin{array}{c}0.23 \\
(0.06)\end{array}$ & $\begin{array}{l}\text { n.a. } \\
\text { n.a. }\end{array}$ & $\begin{array}{c}3.63 \\
(0.70)\end{array}$ \\
\hline Real cost overrun & $\begin{array}{l}\text { n.a. } \\
\text { n.a. }\end{array}$ & $\begin{array}{l}\text { n.a. } \\
\text { n.a. }\end{array}$ & $\begin{array}{l}0.01 \\
(0.01)^{a}\end{array}$ & $\begin{array}{l}\text { n.a. } \\
\text { n.a. }\end{array}$ & $\begin{array}{c}0.14 \\
(0.14)=\end{array}$ \\
\hline $\begin{array}{l}\text { Regression statistics (OLS) } \\
\text { Adiuged } R 2\end{array}$ & & & & & \\
\hline $\begin{array}{l}\text { Adjusted } R^{2} \\
\text { F-statistic }\end{array}$ & $\begin{array}{c}0.19 \\
240^{-19}\end{array}$ & $\begin{array}{l}0.19 \\
80\end{array}$ & $\begin{array}{c}0.20 \\
64.6\end{array}$ & $\begin{array}{l}0.0012 \\
0.59\end{array}$ & $\begin{array}{r}0.032 \\
11.029\end{array}$ \\
\hline $\begin{array}{l}\text { Chi-square statistic } \\
\text { (critical value for } \\
1 \text { percent level) }\end{array}$ & $\begin{array}{l}13.1^{\mathrm{b}} \\
(9.2)\end{array}$ & $\begin{array}{r}26.8^{b} \\
(21.7)\end{array}$ & $\begin{array}{l}40.8^{b} \\
(29.1)\end{array}$ & $\begin{array}{l}9.38 \\
(15.1)\end{array}$ & $\begin{array}{l}17.4 \\
(21.7)\end{array}$ \\
\hline F-test of the regression & n.a. & 0.7 & $5.0<$ & n.a. & $28.8^{d}$ \\
\hline
\end{tabular}

n.a. Not applicable.

Note: Sample size is 1,015 for all five models. Values in parentheses are the standard errors.

2. Not significant at the 5 percent level.

b. Presence of heteroskedasticity at the 1 percent level of significance.

c. Regression fit improved with respect to model 1.

d. Regression fit improved with respect to model 4.

Source: Authors' calculations.

a project with an appraisal rate of return of 30 percent has, on average, a reestimated rate of return of 19 percent $(5.88+0.44 \times 30)$. As indicated by the low values of standard errors of estimates, both the intercept and the parameter estimate for AERR are statistically highly significant. However, the appraisal rate of return explains only 19 percent of the variance, which indicates a rather loose relation between rate of return estimates at appraisal and completion of construction, already shown in figure 1 .

Model 2. In model 2 parameter estimates for nominal cost overrun and time overrun are small and statistically insignificant, thus indicating that nominal cost overruns and implementation delays do not seem to be major factors in explaining divergences in the rates of return.

Model 3. In model 3 the real cost overrun parameter remains low and statistically insignificant, while the unexpected inflation variable is statistically significant. Since unexpected price increases have been expressed as negative numbers 
(reduction in the real value of available project resources), the parameter estimate implies that for projects with (the average) unexpected increase in the price level of 20 percent, rates of return have been reduced by 4.6 percentage points. The results seem to suggest that real increases in project cost have had no systematic effect on rates of return of World Bank projects. Unexpected inflationary pressures have adversely affected the performance of Bank projects, perhaps because of relative price changes between capital-good inputs and project outputs.

Regression of model 3 also yields a statistically significant estimate of the time overrun variable, which, surprisingly, has the wrong sign. If, for example, it takes an average project 58 percent more time to be completed than forecasted at appraisal, one can expect that this would improve the RERR by about 0.7 percentage points. According to this result, the systematic bias toward underestimating the time needed for project completion may be based on the wrong intuitive assumption that long periods of implementation are bad for project performance. However, the modest positive effect that time overruns have on project performance must be weighted against the much bigger negative cost effects stemming from unexpected inflation.

Only the introduction of the decomposed cost overrun variables in model 3 improves the regression fit compared with model 1 , as shown by the $F$-test for additional regressors. But the adjusted coefficient of determination $\left(\bar{R}^{2}\right)$ improves by only one percentage point (from 19 to 20 percent). The chi-square statistic for the White test (see White 1980) indicates the presence of heteroskedasticity at the 1 percent test level.

Model 4. In model 4, which has the transformed dependent and explanatory variables, the estimated regressions have no heteroskedasticity at the 1 percent test level. However, the nominal cost and time overrun parameters are not statistically significant, and the estimated parameters have the wrong sign.

Model 5 . In model 5 the decomposition of nominal cost overruns into unexpected inflation and real cost overruns helps somewhat, because the parameter estimate for the unexpected inflation variable now is statistically significant and has the expected (positive) sign (faster than expected inflation is a negative number). An unexpected price increase of 20 percent (the average for the sample) would thus give rise to a 73 percent discrepancy in the rates of return. However, although model 5 significantly improves the otherwise poor fit of model 4 , the total explained variance of only 3 percent remains surprisingly low.

Project-specific real cost overruns thus do not seem to affect ex-post rates of return as adversely as one would expect. This may be due to the possibility that projects with large real cost overruns (up to almost 400 percent) reflect mostly expansions of projects, rather than errors in cost estimates. To the extent that project expansions lead to efficiency gains, one would expect improvements in the rate of return from such mislabeled "real cost overruns." 
Table 3. Maximum Likelihood Estimates for the Expanded Models

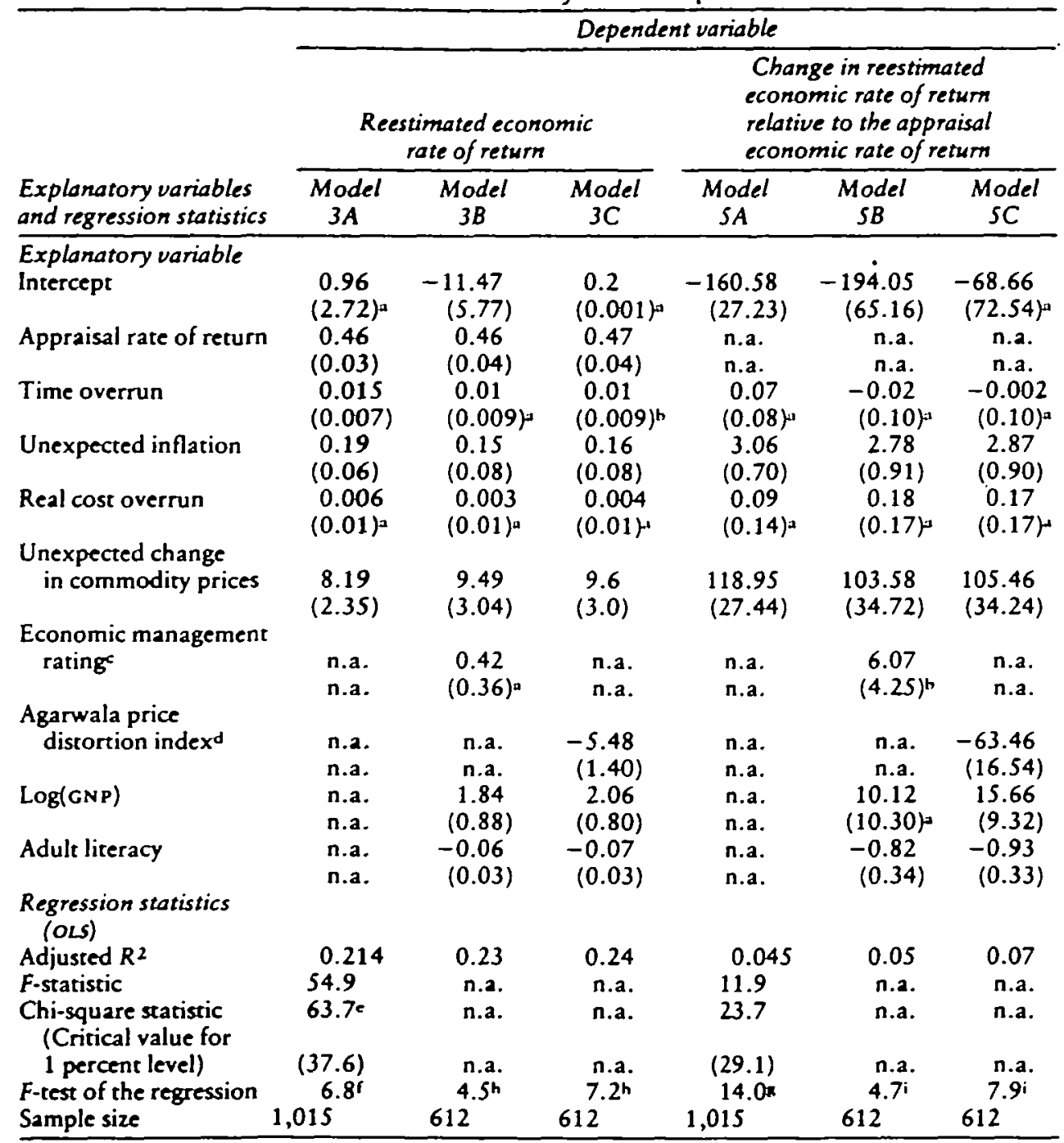

n.a. Not applicable.

Note: Values in parentheses are the standard errors.

a. Not significant at the $S$ percent level.

b. Not significant at the $S$ percent level, but significant at the 10 percent level.

c. As of 1978, on a scale of 1 to 10; lowest actual rating is 2 .

d. Ranges from 1.14 for Malawi (lowest distortion) to 2.86 for Ghana (highest distortion).

e. Presence of heteroskedasticity at the 1 percent test level.

f. Regression fit improved with respect to model 3.

g. Regression fit improved with respect to modet $S$.

h. Regression fit improved with respect to model $3 A$, adjusted for sample size.

i. Regression fit improved with respect to model SA, adjusted for sample size. Source: Auchors' calculations. 


\section{Changes in Primary Commodity Prices}

Since about 40 percent of the projects in the sample are agricultural projects, unexpected changes in commodity prices might explain a substantial part of the gap in the rates of return. We have chosen the ratio of the Bank's real commodity price index for 33 primary commodities (excluding energy) at project completion to the same index at the time of project appraisal as a measure of the extent of unexpected commodity price changes during project implementation. This measure is based on an adaptive expectations model of price expectations at the World Bank (see the appendix). Since the Bank's real commodity price index is deflated by the index of unit value of manufactured exports (MUV) of industrial countries, collinearity between the unexpected commodity price changes variable and the other price variables has been eliminated.

Table 3 gives the results of regressions of models 3 and 5 with this additional explanatory variable in the columns labeled model $3 \mathrm{~A}$ and model $5 \mathrm{~A}$. The estimate for the unexpected commodity price changes variable is statistically significant, and its inclusion improves the fit of the regression, as measured by the $F$-test, with respect to models 3 and 5 . The explained variance $\left(R^{2}\right)$ increases by about 1.5 percentage points, which is quite respectable compared to regressions with other variables, but the unexplained variance nevertheless remains very large.

The unexpected commodity price changes are measured as an index number, so no change corresponds to the index value of 1.0 , and a 10 percent change corresponds to the index value of 1.1 or 0.9 . The parameter estimates imply that an unexpected decline in commodity prices by 10 percent would reduce the rate of return by 0.8 percentage points $[8.19 \times(1.0-0.9)]$ in model $3 \mathrm{~A}$, or 12 percent $(118.95 \times 0.1)$ in model $5 \mathrm{~A}$. In model $5 \mathrm{~A}$ the high estimated values of the intercept term $(-161)$ and the commodity price parameter (119) actually must be set against each other for the zero expected price change to give, approximately, the intercept term from model $5(-41)$. The same would hold true of model $3 \mathrm{~A}$ if the intercept estimate was statistically significant.

A similar analysis was carried out for agricultural projects, using a real agricultural commodity price index, and the results were analogous. The use of individual commodity price indexes (such as a coffee price index for coffee projects) probably would show the greater sensitivity of some types of projects to specific commodity price changes, but the number of observations is too small to permit much further disaggregation. Also many agricultural projects are multi-purpose projects (for example, irrigation) for which the broad commodity price index may be more useful.

\section{Economic Management Factors}

A second set of factors that could help explain some of the divergence in rateof-return estimates between the appraisal and completion of construction are the country-specific factors, such as the human resource endowment, the type of 
economic policies pursued by the government, and the efficiency of public administration. Of course these are complex factors that are not easily measurable. We have to make do with a few quantitative indicators, such as adult literacy, per capita income, an index of price distortions for the 1970s (Agarwala 1983), and the Bank's internal ranking of the quality of government economic policies and management (as of 1978, taken as representative for the 1970s).

These factors should have been taken into account by project evaluators and factored into the appraisal estimate of the rate of return and, more important, into project design (for example, the extent of project management services provided by expatriates, which is one way of ensuring the success of the project). The parameter estimates for these variables thus need to be interpreted as the degree to which project evaluators did not sufficiently take account of these factors. In all cases it can be reasonably assumed that project evaluators were aware of these country-specific factors at the time of appraisal. Only in the case of the Agarwala price-distortion index could one possibly argue that there is some benefit of hindsight at work, because the extent of price distortions and their negative consequences may not have been fully appreciated. But Agarwala's index is based mostly on relatively easily available economic data that (at least in their raw form) were already available at appraisal. Moreover the Bank's internal rating of economic management performance is fairly closely related to the price distortion index (the coefficient of correlation between the two ratings is -0.67 ).

The results of regressions with country-specific variables added (models 3B, $3 \mathrm{C}, 5 \mathrm{~B}$, and $5 \mathrm{C}$ ) are shown in table 3 . The implementation delay and decomposed cost-overrun variables from models $3 \mathrm{~A}$ and $5 \mathrm{~A}$ have been retained. The Bank's economic management rating is an explanatory variable in models 3B and 5B; the Agarwala price distortion index is in models 3C and 5C. Most of the new variables are statistically significant.

The Agarwala price-distortion index performs statistically considerably better than the Bank's rating of economic management performance. This is surprising, since the latter is based on the same economic data plus management's judgments based on qualitative insights. Apparently the relatively simplistic procedure of adding up price distortions works better than a careful review process using qualitative judgments. In all model specifications, replacing the economic performance rating with the price distortion index results in statistically significant parameter estimates, a higher $R^{2}$, and considerably higher values of $F$-tests for inclusion of the new regressors. For the actual range of the price distortion index (from 1.14 to 2.86 ), the parameter estimates imply a 9.4 [(2.86-1.14) $\times(-5.48)]$ percentage points (model 3C) lower RERR in a country with high price distortions (such as Ghana during the 1970s), compared with a country with low price distortions (such as Malawi). The adverse effects on project performance of government interventions through price controls, high tariffs, import restrictions, and so forth thus have been considerably underestimated in World Bank project appraisals. 
Poor economic management and price distortions explain only about 2 percent of the rate-of-return gap, however, inching the total explained variance (model 3C) to only 24 percent. The level of income and adult literacy variables have been introduced as (albeit crude) indicators of the human capital stock, and their parameter estimates are statistically significant. Thus if per capita income decreases from $\$ 1,000$ to $\$ 500$, ex-post rates of return are lower by about 1.4 percentage points (model $3 \mathrm{C}$ ), or about 11 percent (model $5 \mathrm{C}$ ). ${ }^{3}$ This suggests that the Bank's project evaluators have tended to overestimate project implementation capabilities in the poorest countries. Surprisingly, the parameter estimate for the adult literacy variable has the wrong sign, indicating that reestimated rates of return are lower in countries with higher adult literacy rates (for similar projects and levels of income). This can be explained by the fact that countries with high rates of literacy tend to engage in projects involving more sophisticated technology, which brings higher rates of return, but at higher risk, so that the rate-of-return discrepancy also is greater.

\section{Sectoral and Geographic Differences}

There are several ways to analyze the differences between the various types of projects. One is to introduce dummy $(0,1)$ variables comparing different groups of projects. Another approach would be to run the same set of regressions on different sectoral or geographic subsets of projects to see whether there are statistically significant differences in parameter estimates. Table 4 presents estimates of regressions with both sectoral and regional dummy variables added to models $3 \mathrm{~B}$ and $5 \mathrm{~B}$, now labeled $3 \mathrm{D}$ and $5 \mathrm{D}$, respectively. Although it would have been preferable to use models $3 C$ and $5 C$ instead of $3 B$ and $5 B$ (because the Agarwala index performs better), this would have limited the sample to only 31 countries and 612 projects, instead of the entire sample of 1,015 projects. Agriculture and South Asia were selected as the standard to which other sectors and regions are compared, so parameter estimates for sectoral and regional dummy variables indicate how, for example, the energy projects or projects in the Mediterranean region perform relative to agricultural projects in South Asia.

The explanatory power of both regressions increases considerably after dummy variables are introduced (from an adjusted $R^{2}$ of 0.21 to 0.31 for model $3 \mathrm{D}$ and from 0.03 to 0.12 for model SD). These variables thus contribute more to the improved regression fit than all the previously introduced variables together (except for the appraisal rate of return in models 1 to 3 ). There thus appear to be clusters of projects with similar characteristics and problems.

Parameter estimates for sectoral dummy variables show that projects in our data sample fall roughly into two categories. Since the estimates for the intercept (that is, agriculture), energy, and industry all are insignificant, the results of model 3D indicate that, other things being equal, projects with an appraisal rate

3. Calculated as $2.06(\ln 1,000-\ln 500)=1.43 ;$ and $15.66(\ln 1,000-\ln 500)=10.85$, respectively. 
Table 4. Regressions with Sectoral and Regional Dummy Variables

\begin{tabular}{|c|c|c|}
\hline \multirow{3}{*}{$\begin{array}{l}\text { Explanatory variables } \\
\text { and regression statistics }\end{array}$} & \multicolumn{2}{|c|}{ Dependent variable } \\
\hline & $\begin{array}{l}\text { Reestimated economic } \\
\text { rate of return }\end{array}$ & $\begin{array}{l}\text { Change in reestimated } \\
\text { economic rate of } \\
\text { return relative to the } \\
\text { appraisal economic } \\
\text { rate of return }\end{array}$ \\
\hline & Model 3D & Madel SD \\
\hline $\begin{array}{l}\text { Explanatory variable } \\
\text { Intercept } \\
\text { Appraisal rate of return } \\
\text { Time overrun } \\
\text { Unexpected inflation } \\
\text { Real cost overrun } \\
\text { Unexpected change in commodity } \\
\text { prices } \\
\text { Economic management rating } \\
\text { Log(GNP) } \\
\text { Adult literacy }\end{array}$ & $\begin{array}{l}0.45^{a} \\
0.43 \\
-0.007 a \\
0.12 \\
0.006 \\
6.45 \\
0.83 a \\
-0.50 \\
-0.04 b\end{array}$ & $\begin{array}{c}-175.15 \\
\text { n.a. } \\
-0.07 \\
2.55 \\
0.12 \\
90.49 \\
\\
6.53 \\
11.94 \\
-0.73\end{array}$ \\
\hline $\begin{array}{l}\text { Sectoral dummy variable } \\
\text { Energy } \\
\text { Transport } \\
\text { Industry } \\
\text { Urban }\end{array}$ & $\begin{array}{c}0.96 \\
7.62 \\
-0.88^{\star} \\
9.51\end{array}$ & $\begin{array}{c}27.41 \\
63.58 \\
-29.51^{b} \\
-8.55^{a}\end{array}$ \\
\hline $\begin{array}{l}\text { Regional dummy variable } \\
\text { East Africa } \\
\text { CFA countries } \\
\text { Other West Africa } \\
\text { East Asia } \\
\text { Mediterranean } \\
\text { Latin America }\end{array}$ & $\begin{array}{r}-12.54 \\
-8.02 \\
-9.92 \\
-3.64 \\
-6.92 \\
-7.11\end{array}$ & $\begin{array}{l}-94.82 \\
-52.88 \\
-96.87 \\
-24.242 \\
-62.33 \\
-63.04\end{array}$ \\
\hline $\begin{array}{l}\text { Regression statistics (OLS) } \\
\text { Adjusted } R^{2} \\
F \text {-test of the regression. }\end{array}$ & $\begin{array}{l}0.309 \\
13.6^{c}\end{array}$ & $\begin{array}{l}0.121 \\
8.1^{d}\end{array}$ \\
\hline
\end{tabular}

n.a. Not applicable.

Note: Sample size 1,015 projects for both models.

a. Not significant at the 5 percent level.

b. Not significant at the $\mathbf{S}$ percent level, but significant at the $\mathbf{1 0}$ percent level.

c. Regression fit improved with respect to model 3B.

d. Regression fit improved with respect to model SB.

Source: Authors' calculations.

of return of, say, 20 percent that are undertaken in these three sectors are expected to have a RERR of about 9 percent $(20 \times 0.43)$, or 11 percentage points below the estimate. However, transport projects are expected to have a RERR about 4 percentage points below the estimate $(7.62+[20 \times 0.43])$, and urban development projects about 2 percentage points below the estimate $(9.51+[20$ $\times 0.43]$ ). This pattern is roughly confirmed by the results of model $S D$, where the greatest rate-of-return discrepancy is for industry, there is less discrepancy for agriculture and energy projects, and transport projects again have the lowest discrepancy in economic rates of return. (Correct interpretation of the figures in 
table 4 is more complicated, though, because we neglected the term $\sigma \epsilon_{i}$ [(equation 2)]; the scale parameter for model $3 D$ is $\mathbf{1 1 . 4}$, and for model SD it is 113.)

Reestimated rates of return for projects in the transport and urban development sectors thus are generally closer to the appraisal rates of return than are projects in agriculture, energy, and industry. This pattern probably reflects two factors: the relatively simple technology and organization of transport and urban development projects compared with industrial and energy projects and the effect of international markets on industrial and agricultural projects. Projects producing traded goods seem to be exposed to a higher degree of downside risks, and this may be related to international competition (that is, competitors in other countries may be more productive, and this may lead to lower prices for outputs and sharply lower returns).

Parameter estimates for regional dummy variables all have a negative sign, implying that reestimated rates of return are highest in South Asia (the standard of comparison), followed by the projects in East Asia, with slightly lower (3.6 percent) rates of return. Projects in Latin America, the Mediterranean, and Francophone Africa (CFA) are next on the list, while projects in East and West Africa (other than the CFA zone) have performed particularly poorly. The better performance of CFA members compared with other African countries points to the importance of the institutional framework and, in particular, the conservative monetary policies. The project implementation performance in CFA member countries during the 1960 s and 1970 s is comparable with the average of developing countries in the Mediterranean and Latin America.

An analysis of failed projects indicates that out of 80 total project failures (that is, negative rates of return at project completion), 27 are in East Africa, with Tanzania alone accounting for 11 . Failed projects are concentrated largely in agriculture, as nearly two-thirds of all project failures worldwide have been agricultural projects, particularly complex new-style area or rural development projects started in the mid-1970s (table 5). Agricultural projects in Sub-Saharan Africa have an unacceptable failure rate, with one-half of all projects in East Africa and more than one quarter of all projects in West Africa yielding reestimated rates of return below 5 percent. There is a strong distinction in West Africa between CFA members and other countries.

A more informative approach to the analysis of the regional performance of projects is to run regressions for each sector separately (table 6). Compared with the combined sample (table 4), the disaggregated regressions by sector have fewer statistically significant parameters, and parameter estimates for some variables are very different from sector to sector. For the appraisal rate of return, the parameter estimates are relatively high for infrastructure projects $(0.61-0.67)$ and low for agricultural and industrial projects $(0.21-0.25)$. Thus downside risks are larger (or have been underestimated) in the directly productive sectors. Unexpected movements in primary commodities (excluding energy) seem to have affected industrial projects even more than agricultural projects (most of the industrial projects in the sample are import-substituting raw materials projects, such as in the fertilizer industry). 
Table 5. Project Failures by Region and Sector

\begin{tabular}{lccc}
\hline & \multicolumn{3}{c}{$\begin{array}{c}\text { Percentage of projects with reestimated } \\
\text { rates of retum below }\end{array}$} \\
\cline { 2 - 4 } & 10 percent & S percent & Opercent \\
\hline All projects & 25.2 & 13.6 & 7.9 \\
East Africa & 41.1 & 27.9 & 17.1 \\
West Africa & & & \\
CFA member countries & 21.8 & 18.2 & 10.0 \\
Other West Africa & 37.5 & 19.6 & 16.1 \\
Mediterranean & 29.1 & 14.3 & 7.4 \\
Latin America & 25.1 & 10.2 & 5.1 \\
South Asia & 14.7 & 6.4 & 1.1 \\
East Asia & 12.5 & 5.2 & 4.2 \\
Agricultural projects & 29.0 & 19.8 & 12.7 \\
East Africa & 61.4 & 52.9 & 37.1 \\
CFA members & 34.0 & 26.0 & 16.0 \\
Other West Africa & 45.8 & 33.3 & 29.0 \\
\hline
\end{tabular}

Source: Authors' calculations.

Table 6. Regressions by Sector

\begin{tabular}{|c|c|c|c|c|}
\hline & \multicolumn{4}{|c|}{ Dependent variable: RERR (model 3D) } \\
\hline & Agriculture & Energy & Transport & Industry \\
\hline $\begin{array}{l}\text { Explanatory variable } \\
\text { Intercept } \\
\text { Appraisal rate of return } \\
\text { Time overtun } \\
\text { Unexpected inflation } \\
\text { Real cost overrun } \\
\text { Unexpected change in commodity } \\
\text { prices } \\
\text { Economic management rating } \\
\text { Log (GNP) } \\
\text { Adult liceracy }\end{array}$ & $\begin{array}{c}6.66^{\mathrm{a}} \\
0.21 \\
-0.02^{\mathrm{a}} \\
0.11^{\mathrm{a}} \\
0.03 \\
\\
11.12 \\
0.61^{\mathrm{a}} \\
0.82^{\mathrm{a}} \\
-0.09\end{array}$ & $\begin{array}{c}10.26^{\mathrm{b}} \\
0.61 \\
0.002^{\mathrm{a}} \\
0.29 \\
-0.02^{\mathrm{a}} \\
\\
1.92^{\mathrm{b}} \\
1.17^{\mathrm{a}} \\
-1.21^{\mathrm{a}} \\
0.03^{\mathrm{a}}\end{array}$ & $\begin{array}{c}7.36^{\mathrm{a}} \\
0.67^{\prime} \\
-0.01^{\star} \\
0.11^{\star} \\
-0.01^{\mathrm{a}} \\
\\
4.36^{\mathrm{a}} \\
0.52^{\mathrm{a}} \\
0.62^{\mathrm{a}} \\
-0.03^{\mathrm{a}}\end{array}$ & $\begin{array}{c}-15.55 \\
0.25 \\
-0.02 a \\
-0.05 \\
-0.04 \\
\\
15.72 \\
-1.72 \\
2.35 \\
0.10^{b}\end{array}$ \\
\hline $\begin{array}{l}\text { Regional dummy variable } \\
\text { East Africa } \\
\text { CrA countries } \\
\text { Other Dest Africa } \\
\text { East Asia } \\
\text { Mediterranean } \\
\text { Latin America }\end{array}$ & $\begin{array}{l}-18.18 \\
-12.64 \\
-17.37 \\
-3.29 b \\
-6.34 \\
-8.34\end{array}$ & $\begin{array}{l}-5.09 \\
2.91 \mathrm{a} \\
-7.89 \\
-4.42^{\mathrm{b}} \\
-7.46 \\
-6.76\end{array}$ & $\begin{array}{l}-12.83 \\
-10.38 \\
-6.33^{b} \\
-7.65 \\
-7.38 b \\
-6.97 b\end{array}$ & $\begin{array}{l}-14.06 \\
\text { n.a. } \\
\text { n.a. } \\
5.24 b \\
-4.11 . \\
-2.81 .\end{array}$ \\
\hline $\begin{array}{l}\text { Regression statistics (OLS) } \\
\text { Adjusted } R^{2} \\
\text { Adjusted } R^{2} \text { without regional } \\
\text { dummies } \\
\text { Sample size }\end{array}$ & $\begin{array}{l}0.25 \\
0.11 \\
411^{0}\end{array}$ & $2^{0.29}$ & $\begin{array}{l}0.29 \\
310^{-2}\end{array}$ & $\begin{array}{l}0.03 \\
56\end{array}$ \\
\hline
\end{tabular}

a. Not s:gnificant at the $S$ percent level.

b. Not significant at the 5 percent level, but significant at the 10 percent level.

Source: Authors' calcularions. 
Unexpected inflation seems to have affected particularly the more capitalintensive infrastructure projects but may also reflect delayed adjustments in government price regulations in the electric power sector, where the Bank's methodology does not conform to the principles of cost-benefit analysis. The economic management rating also shows some perplexing sectoral differences, with a negative parameter estimate for industrial projects, which may be the consequence of a few conspicuous project failures in countries with high performance ratings. A separate analysis for agricultural projects showed that the Agarwala price distortion index performs dramatically better than the economic performance ranking in that sector.

\section{TRENDS OVER TIME}

An analysis of appraisal and reestimated rates of return by year of approval shows that the gap in the rate of return has increased considerably over time (figure 2). Projects appraised in the 1960s showed little difference between average rates of return at appraisal and completion, and annual variations were tracked quite closely. Appraisal and reestimated rates of return started to diverge in the early 1970s. The main cause appears to have been the increasing optimism

Figure 2. Rates of Return by Year of Approval, 1961-80

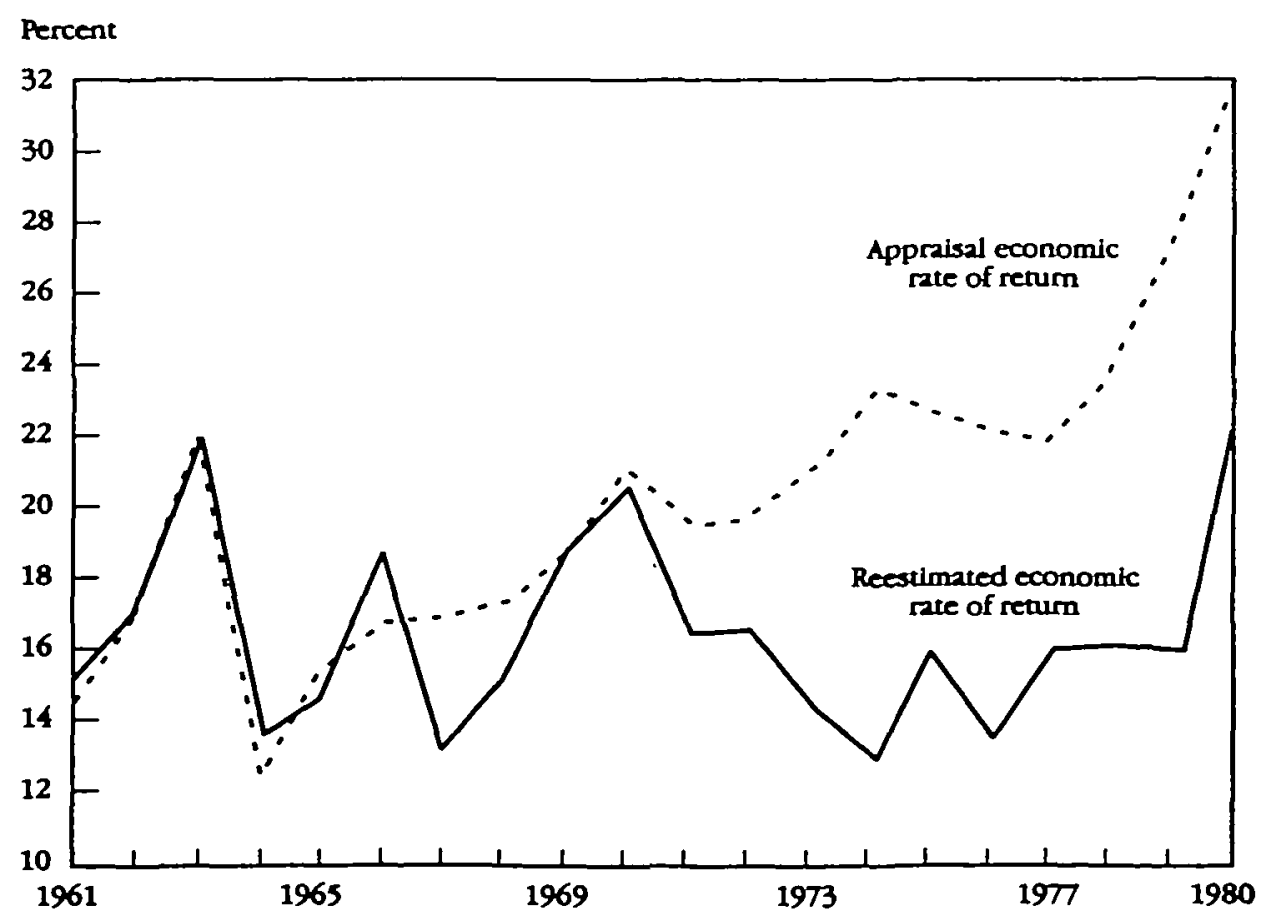

Source: Authors' calculations. 
of project evaluators, with average appraisal rates of return rising from about 16 percent for projects evaluated in the mid-1960s to 20-25 percent for projects evaluated in the mid- and late 1970s. By contrast, average rates of return at project completion showed a persistent downtrend for projects appraised during 1970-76 before recovering again for projects appraised around 1980 (and evaluated in 1985-87).

The downtrend in average reestimated rates of return for projects appraised in the early 1970s was most likely due to external circumstances, that is, the recession and low commodity prices at the time these projects were completed in the late 1970 s and early 1980 s. The increasing rates of return at appraisal during the 1970 s probably reflect internal Bank factors, including the shift in Bank lending from infrastructure to agriculture and industry. In terms of average outcomes at project completion, the vastly expanded lending program of the 1970 s does not compare too unfavorably. Reestimated rates of return for the 1970 s are not very different from those for the 1960s. The sharp increase in reestimated returns for projects appraised in 1980 must be interpreted with caution, because it includes only a small percentage of projects of that appraisal year.

\section{Conclusions}

The statistical analysis of rates of return estimates before and after completion of project construction provides several interesting insights. First, it points to the large degree of uncertainty surrounding the rate-of-return estimates. Second, World Bank appraisal estimates of rates of return are biased, that is, too optimistic. If this degree of optimism is shared by other project evaluators, one should expect that the discount rate that just rations investment projects to the funds available exceeds the ex-post rate of return by a considerable margin. The analytical treatment of project risks thus deserves more attention in practice. Anderson and Quiggin (1990), for example, argue that project implementation variables usually enter project analysis on a "no surprises" basis, corresponding to the modal value of the distribution of possible outcomes. Since surprises are mostly unpleasant, the probability distribution of project implementation outcomes is skewed (a longer tail in the downside direction). If one were to allow for the skewed distribution ("bad surprises"), one could correct the bias in the estimate.

However, factors that have conventionally been associated with this bias (such as cost overruns and implementation delays) seem to explain only a very small part of the unexpected changes in project performance (measured by the rate of return gap). Interestingly, uncertainties seem to be higher in the directly productive sectors (such as agriculture and industry), where rates of return can be altered through external market forces or domestic policy shocks. Rate-ofreturn estimates seem to be more stable for infrastructure projects.

As an alternative to correcting modal estimates of implementation variables 
for "bad surprises," one could set different minimum rate-of-return criteria for different types of project (for example, 10 percent for transport, but 15 percent for agricultural and industrial projects), based on observed divergences in rates of return.

The analysis also has pointed to the importance of the policy environment for successful project implementation. The economic management rating and price distortion variables both indicate that project evaluators did not take the adverse effects of poor economic policies at the macroeconomic level sufficiently into account. More puzzling though, is the fact that regional dummy variables also seem to operate partly as economic management variables and have considerably more explanatory power than direct indicators of the quality of economic management and institutions.

The fact that projects in CFA member countries seem to perform almost as well as those in other regions shows that the high failure rate of projects elsewhere in Sub-Saharan Africa seems to be related primarily to policies and institutions. However, the better performance of projects in CFA countries during the 1960s and the $1970 \mathrm{~s}$ is no guarantee that this will be repeated during the $1980 \mathrm{~s}$, because the external competitiveness of the CFA zone has considerably deteriorated.

The analysis of observed rate-of-return divergences raises more questions than it can answer. The high degree of revealed uncertainty also raises the question whether, and what kind of, improvements in the methodology will contribute to better investment decisions.

\section{Appendix. Derivation of Project Data in Constant Prices}

Project cost estimates for World Bank projects are made in current U.S. dollars, since this is the unit of account for the Bank. Appraisal estimates for a project are made on the basis of prevailing prices at the time of appraisal, a forecast of price changes for internationally traded capital goods (in terms of U.S. dollars), and the projected expenditure (disbursement) profile. Project cost estimates also include a physical contingency for unexpected expenditures. Project costs at project completion are, similarly, the sum of annual expenditures in (actual) current prices ("mixed year dollars").

In periods of unexpectedly high inflation (or for projects with significant implementation delays) reestimated nominal project costs sometimes are substantially higher than appraisal estimates, but real project costs may not have increased at all. To separate nominal from real cost overruns, we derived real (constant price) cost estimates for each project for both appraisal and project completion, by deflating yearly project expenditures with the projected and actual price index for capital goods (the Bank's manufactured unit value (MUV) index for exports of manufactured goods of industrial countries).

Although forecasts for the muv index were available for the past 10 years, we did not have earlier forecasts and had to estimate the price contingency vectors. 
Visual inspection of price forecasts for the past 10 years suggested that the Bank's price forecasts followed a pattern of "adaptive expectations": projections seemed to be based on recent price trends. Several adaptive expectations models were tested, and we found that the projections were best approximated by a fiveyear moving average adaptive expectations model.

The first stage prediction of the Muv index was made by calculating the fiveyear moving average:

$$
\mathrm{MUV}^{\prime}=\frac{\left[\mathrm{MUV}_{t-1}+\ldots+\mathrm{MUV}_{t-s}\right]}{5} .
$$

The moving average values (MUV') were then used to calculate the average deviation from the actual value of the index $\left(M_{U V}^{\prime}-M U v\right) / M U v$, and this estimate was used as a correction parameter, $\beta$, in the adaptive expectations model:

$$
\mathrm{MUV}_{t}^{*}=\mathrm{MUV}_{t-1}^{\prime}+\beta\left(\mathrm{MUV}_{t-1}-\mathrm{MUV}_{t-1}^{\prime}\right), \quad 0<\beta<1 .
$$

That is, the forecasting error for the previous period, $\mathrm{MUV}_{t-1}-\mathrm{MUV}_{t-1}^{\prime}$, is corrected with a fraction $\beta$ (the average error), thereby improving upon ("adapting to") the first-stage forecast.

The real cost at appraisal price projections, $p^{a}$, is then:

$$
X^{a}\left(p^{a}\right)=\sum_{j=1}^{m} \frac{c^{a} / t^{a}}{p_{j}^{a}}
$$

where $X^{a}$ is real cost at appraisal, $t^{a}$ is projected duration of project implementation, $c^{a}$ is nominal cost estimate at appraisal, and $p_{j}^{a}$ is projected price vector at appraisal. The real cost at actual prices is

$$
X^{c}\left(p^{c}\right)=\sum_{j=1}^{\kappa} \frac{c^{c} / t^{c}}{p_{j}^{c}}
$$

where $X^{c}$ is real cost based on actual nominal expenditures $\left\langle c^{c}\right\rangle$, actual implementation duration $\left(t^{c}\right)$, and actual prices $\left(p^{c}\right)$.

The real cost overrun is then $\left[X^{c}\left(p^{c}\right)-X^{a}\left(p^{c}\right)\right] / X^{a}\left(p^{c}\right)$, and the unexpected inflation, as defined in the article is $\left[X^{a}\left(p^{c}\right)-X^{a}\left(p^{a}\right)\right] / X^{a}\left(p^{a}\right)$. Unexpectedly high inflation $\left(p^{c}>p^{a}\right)$ is a negative number according to this definition. This is reflected in the minus sign before the percentage sign in the tables with the statistical results.

\section{REFERENCES}

The word "processed" describes informally reproduced works that may not be commonly available through library systems.

Agarwala, Ramgopal. 1983. Price Distortions and Growth in Developing Countries. World Bank Staff Working Paper 575. Washington, D.C. 
Amemiya, Takeshi. 1973. "Regression Analysis When the Dependent Variable Is Truncated Normal." Econometrica 41: 997-1016.

1984. "Tobit Models: A Survey." Journal of Econometrics 24: 215-22.

Anderson, Jack, and John Quiggin. 1990. "Uncertainty in Project Appraisal." Paper presented at the World Bank Conference on Development Economics, Washington, D.C. Processed.

Dasgupta, Partha, Stephen Marglin, and Amartya Sen. 1972. Guidelines for Project Evaluation. New York: UNiDo.

Drèze, Jean, and Nicholas Stern. 1987. "The Theory of Cost-Benefit Analysis." In Alan Auerbach and Martin Feldstein, eds., Handbook of Public Economics. Vol. II. Amsterdam: North Holland.

Greene, William H. 1990. Econometric Analysis. New York: Macmillan.

Judge, George, R. Carter Hill, William Griffiths, Tsoung-Chao Lee, and H. Lürkepohl. 1985. The Theory and Practice of Econometrics. Second Edition. New York: Wiley.

Little, Ian, and James Mirrlees. 1968. Manual of Industrial Project Analysis. Vol. 2. Paris: OECD Development Centre.

- 1974. Project Appraisal and Planning for Developing Countries. New York: Heinemann.

- 1991. "Project Appraisal and Planning Twenty Years On." Proceedings of the World Bank Annual Conference on Development Economics, 1990. Washington, D.C.

Maddala, G. S. 1983. Limited-Dependent and Qualitative Variables in Econometrics. Cambridge University Press.

Ray, Anandarup. 1984. Cost-Benefit Analysis: Issues and Methodologies. Baltimore, Md.: Johns Hopkins University Press.

Reutlinger, Shlomo. 1970. Techniques for Project Appraisal under Uncertainty. Baltimore, Md.: Johns Hopkins University Press.

Squire, Lyn. 1989. "Project Evaluation in Theory and Practice." In Hollis Chenery and Trent Srinivasan, eds., Handbook of Development Economics. Vol. II. Amsterdam: North Holland.

Squire, Lyn, and Herman G. van der Tak. 1975. Economic Analysis of Projects. Baltimore, Md.: Johns Hopkins University Press.

Tobin, James. 1958. "Estimation of Relationships for Limited Dependent Variables." Econometrica 26: 24-36.

Wallace, T. D., Paul Duane, and Tawhid Nawaz. 1987. "Agricultural Project Economic Rates of Return: A Statistical Analysis." Operations Evaluation Department, World Bank, Washington, D.C. Processed.

White, Halbert. 1980. "A Heteroskedasticity-Consistent Covariance Matrix Estimator and a Direct Test for Heteroskedasticity." Econometrica 48: 817-38.

Zellner, Arnold. 1962. "An Efficient Method of Estimating Seemingly Unrelated Regressions and Tests for Aggregations Bias." Joumal of the American Statistical Association 57: 348-68. 
. 